\title{
Experimental study of the parameters of the active tool of a cultivator with a frame in form a flexible tubular element
}

\author{
Nikolay Ustinov ${ }^{1,{ }^{*}, \text { Artem Maratkanov }}{ }^{1}$, and Alexandr Martynenko ${ }^{1}$ \\ ${ }^{1}$ Northern Trans-UralState Agricultural University, Republic str, 6, Tyumen, 625003, Russia
}

\begin{abstract}
The following article presents the results of an experimental definition of the parameters of the active tool of a cultivator with a frame in the form of a flexible tubular element, having a leak-proof hollow tube with a non-round cross-section. By supplying the cavity of the frame with discrete pressure, the free end point with the cultivator point is forced to ripple, which allows the optimal vibration conditions of the cultivator to be established in various physical and mechanical soil properties. It is concluded that the elastic response of the flexible tubular element has a nonlinear nature. This research established the characteristics of the amplitude frequency, the resonance frequency and the speed of the cultivator. Two operating modes have been revealed: pre-resonance mode, having a range of 8 to $11 \mathrm{~Hz}$, and post-resonance mode, having a range of 14 to $31,5 \mathrm{~Hz}$.
\end{abstract}

\section{Introduction}

As it stands, special emphasis is placed on the problem of the use of vibration during soil cultivation, which is the most power-consuming operation in agricultural production. The primary methods of reducing drawbar resistance of cultivating equipment are the application of spring tines and other special materials. However, the usage of the aforementioned methods does not allow the lowering of the drawbar and the improvement of the quality of work when changing the depth or the physical or mechanical properties of working soil without constructive changes to the parameters of cultivators.

The application of forced vibration in cultivation is the most promising direction which allows one to change the parameters of vibration in case of a change in working conditions, which in turn allows one to lower the drawbar and increase the quality of work [1-7]. At the same time, the existing solutions for vibratory drives such as unbalanced vibrators and crank drives have not received widespread recognition due to their specific quantity of metal and unreliability in commissioning. Usage of hydraulic pulse drives is limited by the number of available cultivators which allow work in conditions of substantial pollution and abrasive medium, therefore the development of cultivators capable of transferring

${ }^{*}$ Corresponding author: UstinovNikNik@mail.ru 
pulseimpact to the soil, while not having parts working in frictious contact, happens to be an urgent problem.

As a possible solution to this problem the following design of an active cultivator frame is presented $[8,9]$ - a C-shaped pole made in the form of a flexible tubular part which has a leak-proof flexible tube with a non-round cross-section (Figure 1).

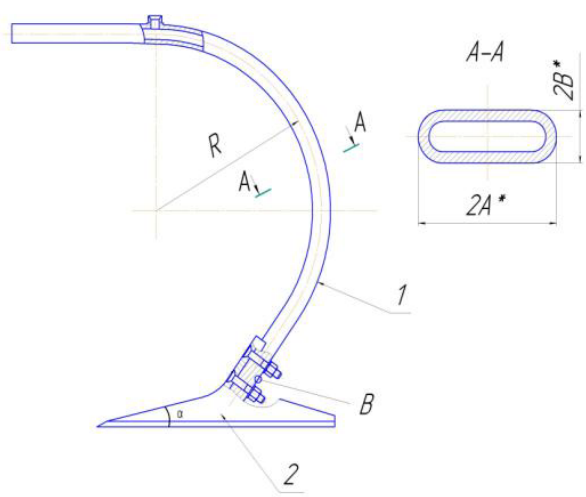

Fig. 1.Active tool of cultivator, where 1 - cultivator point, 2 -frame.

The principle action of the active tool is as follows: with the supplement of pressure to the cavity of the frame(2) through the connecting pipe with working fluid or air, a deformation of the section occurs, and as a result the free end point of the cultivator point 1 is dislocated. With the supplement of discrete pressure the cultivator point ripples with a specific amplitude and frequency, depending on the parameters of the incoming pressure. When changing the parameters of pressure, it is possible to set different modes of rippling, which allows one to lower the drawbar.

The aim of the experimental study is to define the characteristics of the active parts of a cultivator with a leak-proof flexible tube when affected by internal pressure.

\section{Materials and methods}

The experiment was conducted in two steps:

1. The definition of flexible characteristics under the effects of pressure from the cavity of the frame. The measureable parameter chosen for this was the placement angle of the cultivator point $\alpha$ descending (Figure 1).

2. The definition of frequency characteristics under the effects of discrete pressure in the cavity of the frame.

For the purpose of the experiment a laboratory facility was set up. (Figure 2), which consisted of the active tool (1), a manometer (2), a hydro distributor with an electromagnetic valve (3), and frames (4). The hydraulic system is a power impulse system of the hydrovolumetrictype.The formation of the moving force happens as a result of a supplement of pressure to the closed displacement chamber, which causes the pulse pressure to appear in that chamber. The hydraulic system consists of a pumper, a hydro distributor with electromagnetic control, and an overflow valve to support the pressure value in the system. The pulsing frequency is changed by the signal from the controlling electromagnet of the distributor. To carry out the experiment a standard flexible tube was crafted from steel 12XH10T.The geometrical parameters of the aforementioned detail wereas follows (Figure 1): the central axis had a radius $\mathrm{R}=332 \mathrm{~mm}$, the size of the major semiaxis of the tubular member section was $2 \mathrm{~A}^{*}=70 \mathrm{~mm}$, the size of the minor semiaxis of 
the tubular member was $2 \mathrm{~B}^{*}=30 \mathrm{~mm}$; the pipe wall thickness was $4.8 \mathrm{~mm}$; while the mass of the cultivator point was $8.05 \mathrm{~kg}$.

For the definition of the flexible characteristics a pressure of 0 to $5 \mathrm{MPa}$ was supplemented to the cavity of the frame. For the definition of the placement angle of the cultivator point $\alpha$, a pendular goniometer was used (type ЗУРИ-М ТУ-2-034-666-82).

For the definition of frequency characteristics an oscillatory pressure (peak value $A_{p}=5$ $\mathrm{MPa}$ ) with frequencies of $8 ; 12.5 ; 16 ; 31.5 \mathrm{~Hz}$ applied to the cavity of the frame. The device "Vibran 2" was used for the definition of the frame rippling, the amplitude of Ax rippling and the vibration velocity. The magnetic sensor of the device is set up on point B (Figure 1).The registration of the changing parameters of angle $\alpha$ and the ripple parameters were done in a fivefold manner.

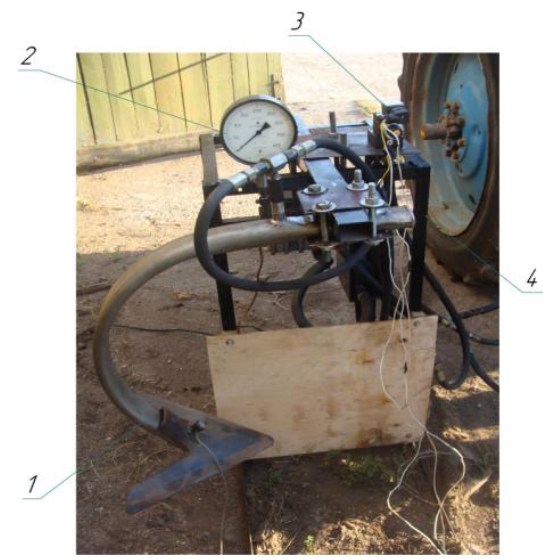

Fig. 2.Laboratory facility, where 1 - active tool, 2 - manometer; 3 - hydrodistributor with an electromagnetic valve; 4 - frame.

\section{Results and Discussion}

The responsiveness of the frame in the form of a flexible tubular part to the internal pressure is one of the most important factors, defining the lead stability of the active tool depth-wise. The value of the nominal operating pressure must provide adeviation of the tip angle $\alpha$ in the constrained optimizations. Figure 3 illustrates the elastic response of the active tool as per the results of the experiment.

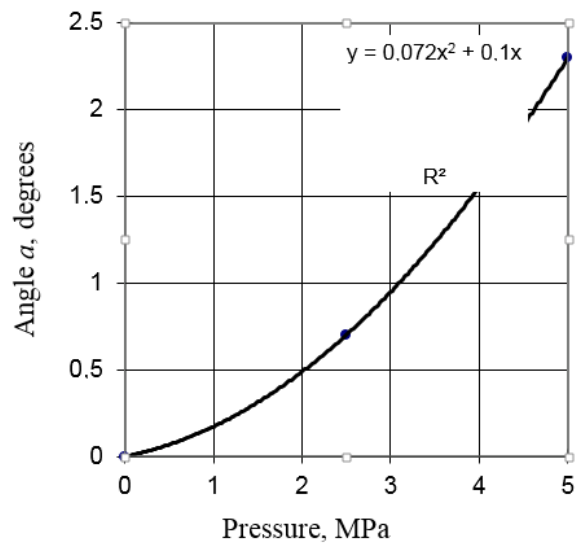

Fig. 3. The elastic response of the active tool with a frame in the form of a flexible tubular element. 
As illustrated in the graph, the elastic response of the flexible tubular part has a nonlinear nature and progresses. The change in angle $\alpha$ with a pressure of $5 \mathrm{MPa}$ does not exceed $2.5^{\circ}$.

Amplitude frequency characteristics of the active tool were formulated as the result of frequencyresponseanalysis; of amplitude frequency (Figure 3) and pulsefrequency characteristics(Figure 4).

It is established that the working tool's active oscillation frequency range is between 8 and $31.5 \mathrm{~Hz}$. The inherent oscillation frequency of the frame is $12.5 \mathrm{~Hz}$. The experiments have shown that working in resonant mode leads to instability, as a drastic increase of oscillation amplitude follows. Two operating modes have been revealed: pre-resonance mode, having a range of 8 to $11 \mathrm{~Hz}$, and post-resonance mode, having a range of 14 to 31.5 Hz. (Figure 3).

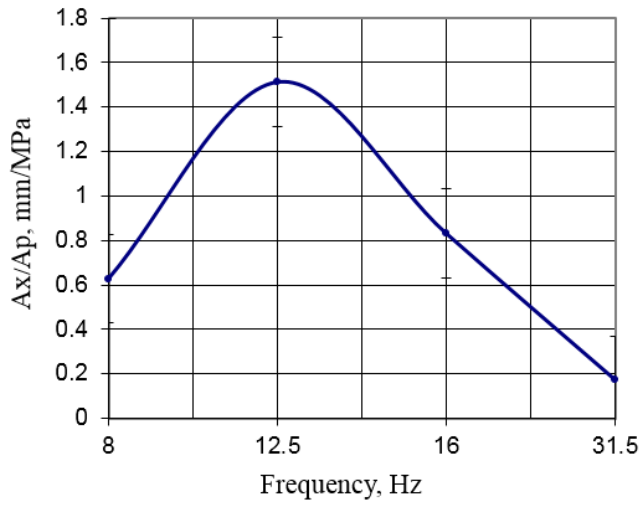

Fig. 4.Amplitude-frequency characteristics of the active tool.

An important characteristic of the impact of the active tool on the soil is pulse.Fig. 4illustrates the pulse frequency characteristics of the active tool. In resonance mode the value of the pulse reaches $3.69 \mathrm{~kg} \cdot \mathrm{m} / \mathrm{s}$. The spread of pulse value in pre-resonance mode is $1 \mathrm{~kg} \cdot \mathrm{m} / \mathrm{s}$ to $3 \mathrm{~kg} \cdot \mathrm{m} / \mathrm{s}$, and in post-resonance mode is $0.9 \mathrm{~kg} \cdot \mathrm{m} / \mathrm{sto} 3.5 \mathrm{~kg} \cdot \mathrm{m} / \mathrm{s}$.

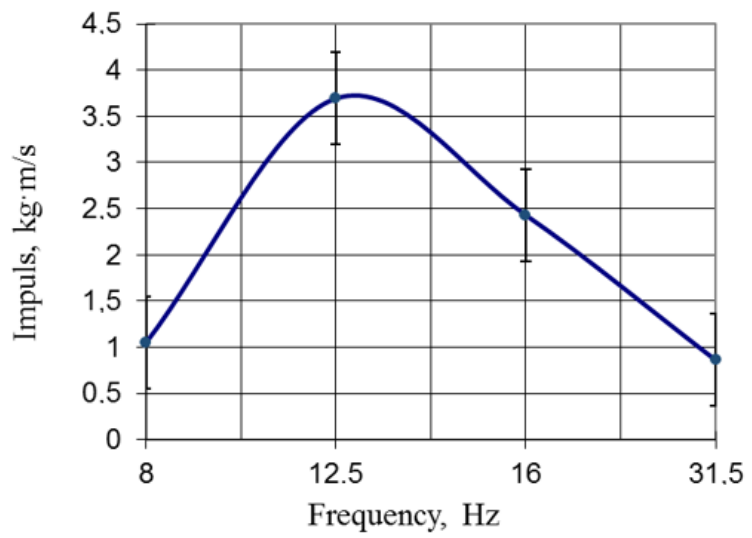

Fig. 5.Pulse-frequency characteristics of the active tool.

\section{Conclusions}

By this line of reasoning, the parameters of the active tool of the cultivator with a frame in the form of a flexible tubular element, having a leak-proof hollow tube with a non-round 
cross-section were defined by experimentation.It is concluded thatthe elastic response of the flexible tubular part has a nonlinear nature. Amplitude frequency and pulse frequency characteristics of the active tool were defined. Two operating modes have been revealed: pre-resonance mode, with a range of 8 to $11 \mathrm{~Hz}$, and post-resonance mode, with a range of 14 to $31.5 \mathrm{~Hz}$.

\section{References}

1. O.Vernyaev, Activetools of cultivators(Mashinostroenie, Moscow, 1983)

2. T. Niyamapa, V.M. Salokhe, Journal of Terramechanics6, 395-403 (1993)

3. T. Niyamapa, V.M. Salokhe, Journal of Terramechanics37, 151-166 (2000)

4. R. Karoonboonyanan, V.M. Salokhe, T. Niyamapa H. Nakashima, Ejournal,18(2007)

5. L. Fenyvesy, Z. Hudoba, ARPN Journal of Agricultural Machinery Science5, 445-449 (2009)

6. S.N. Drozdov, I.Z. Ashirov, A.A. Sorokin, O.Y. Nabokina, IzvestiyaOmskogo GAU 1, 46-48 (2013)

7. M.A. Nagayka, S.G. Shchukin, V.A. Golovatyuk, VestnikAltaiskii state university 6, 110-115 (2015)

8. N. N. Ustinov, Selskiimekhanizator12, 30-31 (2015)

9. N. N. Ustinov, A. A. Maratkanov, N. I. Smolin, Modern problems of science and education, 1 (2015) 